\title{
Correlates of Use and Perceived Effectiveness of Non-pharmacologic Strategies for Chronic Pain Among Patients Prescribed Long-term Opioid Therapy
}

\author{
Crystal C. Lozier, $P h D^{1,2}$, Shannon M. Nugent, $P h D^{1,2}$, Ning X. Smith, $P h D^{3}$, \\ Bobbi Jo Yarborough, PsyD ${ }^{3}$, Steven K. Dobscha, MD ${ }^{1,2}$, Richard A. Deyo, MD, MPH ${ }^{2,3}$, and \\ Benjamin J. Morasco, $P h D^{1,2}$

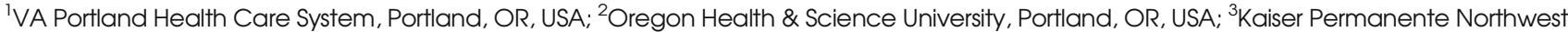 \\ Center for Health Research, Portland, OR, USA.
}

OBJECTIVE: Non-pharmacologic treatments (NPTs) are recommended for chronic pain. Information is limited on patient use or perceptions of NPTs. We examined the frequency and correlates of use and self-rated helpfulness of NPTs for chronic pain among patients who are prescribed long-term opioid therapy (LTOT).

METHODS: Participants $(n=517)$ with musculoskeletal pain who were prescribed LTOT were recruited from two integrated health systems. They rated the frequency and utility of six clinician-directed and five self-directed NPTs for chronic pain. We categorized NPT use at four levels based on number of interventions used and frequency of use (none, low, moderate, high). Analyses examined clinical and demographic factors that differed among groups for both clinician-directed and self-directed NPTs.

RESULTS: Seventy-one percent of participants reported use of any NPT for pain within the prior 6 months. NPTs were rated as being helpful by more than $50 \%$ of users for all treatments assessed (range 51-79\%). High users of clinician-directed NPTs were younger than non-users or low-frequency users and had the most depressive symptoms. In both clinician-directed and self-directed categories, high NPT users had significantly higher pain disability compared to non-NPT users. No significant group differences were detected on other demographic or clinical variables. In multivariable analyses, clinician-directed NPT use was modestly associated with younger age $(\mathrm{OR}=0.97,95 \% \mathrm{CI}=0.96$ $0.98)$ and higher pain disability $(\mathrm{OR}=1.01,95 \% \mathrm{CI}=$ 1.00-1.02). Variables associated with greater selfdirected NPT use were some college education $(\mathrm{OR}=$ $1.80,95 \% \mathrm{CI}=1.13-2.84)$, college graduate or more $(\mathrm{OR}=2.02,95 \% \mathrm{CI}=1.20-3.40)$, and higher pain disability $(\mathrm{OR}=1.01,95 \% \mathrm{CI}=1.01-1.02)$.

CONCLUSIONS: NPT use was associated with higher pain disability and younger age for both clinician-directed and self-directed NPTs and higher education for self-directed NPTs. These strategies were rated as helpful by those that used them. These results can inform intervention implementation and be used to increase engagement in NPTs for chronic pain.

KEY WORDS: chronic pain; non-pharmacologic pain management; longterm opioid therapy.

Published online April 9, 2018
J Gen Intern Med 33(Suppl 1):S46-S53

DOI: $10.1007 / \mathrm{s} 11606-018-4325-\mathrm{x}$

(c) Society of General Internal Medicine (outside the USA) 2018

\section{INTRODUCTION}

Chronic pain affects up to one third of Americans. ${ }^{1}$ Though many individuals with chronic pain are prescribed opioid medications, there is a growing awareness of harms, such as addiction, overdose, and other adverse effects associated with the long-term use of opioids. ${ }^{2,3}$ In an attempt to ameliorate these harms, the Centers for Disease Control and Prevention has provided clinical guidelines for chronic pain management that encourage a combination of non-pharmacologic and nonopioid analgesic medications as the preferred treatment for chronic pain. ${ }^{4}$

Non-pharmacologic treatments (NPTs) for pain can be broadly defined and may include self-directed or clinician-directed treatments and may incorporate complementary and alternative medicine (CAM) and other non-medication-based treatments. ${ }^{5}$ NPTs include therapies such as exercise and movement (e.g., weight training, Tai Chi), physical therapy, transcutaneous electrical nerve stimulation (TENS), chiropractic treatment, acupuncture, herbal medicines, massage, and cognitive behavior therapy (CBT). Among individuals diagnosed with musculoskeletal pain, a considerable amount of literature supports exercise and physical therapy for short- and long-term pain reduction and improvement in physical function. ${ }^{6-11}$ There is also moderate to strong empirical evidence for other interventions for chronic pain, such as yoga, ${ }^{12}$ massage therapy, ${ }^{13,14,15}$, and $\mathrm{CBT}^{16}{ }^{16}$ There is some limited support for other NPTs such as acupuncture $^{17,18,19}$ and Tai Chi. ${ }^{20,21}$ The research on TENS is inadequate to make recommendations. ${ }^{22-25}$

Due to the promising empirical data, combined with greater safety relative to pharmacotherapy and potential health care cost savings among those who use NPTs compared to those who do not, ${ }^{26}$ NPTs are being increasingly recommended. ${ }^{27}$ For individuals with chronic low back pain, NPTs are now recommended by the American College of Physicians as a first-line intervention. ${ }^{25}$ 
Among patients with musculoskeletal pain, estimates of the prevalence of use for various NPTs for pain management range from 6 to $58 \%$, with massage or chiropractic interventions being the most common and yoga or herbal supplements the least common. ${ }^{28-31}$ Some research has attempted to identify variables associated with greater NPT use. An early study found that higher income, younger age, female gender, pain located in the neck and upper back, absence of illicit substance use, and higher current pain intensity were most associated with NPT use for chronic pain. ${ }^{29}$ In addition to limited data about correlates of NPT use, little is known about the perceived benefit of NPT for chronic pain. In a sample of patients prescribed opioids for mixed pain-related diagnoses, the self-reported efficacy of NPT approaches was high; however, few patients reported past-year use, potentially limiting the findings. ${ }^{29}$

As an increasing number of patients discontinue long-term opioid therapy (LTOT), ${ }^{32-34}$ in response to new treatment guidelines, limited data about opioid effectiveness, and increased risk, contemporary data are needed to provide information on the frequency of use, satisfaction, and perceived efficacy of NPTs. These data may help to inform strategies to increase participation in NPTs. The purpose of this study was to examine the frequency of use and perceived utility of clinician-directed and self-directed NPT strategies for patients with musculoskeletal pain who were prescribed LTOT. Furthermore, we sought to identify sociodemographic and clinical factors associated with the level of NPT utilization and patients' satisfaction with use.

\section{MATERIALS AND METHODS}

\section{Settings}

We examined baseline data from an ongoing, multisite prospective cohort study of patients prescribed LTOT; a more detailed description of the research methods has been previously described. ${ }^{35}$ This study was conducted in two large integrated health care systems: Kaiser Permanente Northwest (KPNW) and the VA Portland Health Care System (VAPORHCS). Both settings provide a variety of patient care services and were chosen to reflect a range of patient demographic and clinical factors.

\section{Participants}

Patients with documentation of a musculoskeletal pain diagnosis in their medical records in the past 12 months were eligible for inclusion. Musculoskeletal pain diagnoses were chosen because they comprise the majority of chronic pain conditions. ${ }^{36}$ Participants must also have received a stable dose of at least 90 consecutive days of opioid therapy. ${ }^{37,38}$ We defined a stable dose as having no more than a $10 \%$ change in monthly morphine equivalent dose (MED) during a 90-consecutive day period. Ability to read and write in English was also an inclusion criterion.

Participants were excluded if they reported pending litigation or disability claims related to a pain condition, age younger than
18 years, a cancer diagnosis, enrollment in an opioid agonist treatment program for treatment of opioid use disorder in the prior year, lack of telephone access, or a current opioid dose greater than $120 \mathrm{mg}$ morphine equivalent. We also excluded patients whose only opioid prescriptions were for tramadol.

\section{Study Procedures}

Study procedures were reviewed, approved, and monitored by Institutional Review Boards at both study settings. We identified potential participants using electronic health records (EHR) at both clinical sites, on the basis of past-year ICD-9$\mathrm{CM}$ diagnoses and current prescription opioid medication use. We sent a personalized study invitation letter to each potentially eligible patient that included a description of the study, coordinator contact information, and a prepaid postcard to indicate or decline interest in participation. Study staff followed up by phone to provide additional study details and conduct a brief screening. Individuals who met preliminary inclusion/exclusion criteria and indicated interest in participating were scheduled for baseline assessments. All participants provided written informed consent to participate.

\section{Measures}

Self-report Measures. Basic demographic characteristics included age, gender, race, marital status, education status, employment, socioeconomic status, and disability status.

Use of NPTs for chronic pain was assessed using three single-item questions that were based on prior research and that assessed interventions often used by people with health problems. ${ }^{39-41}$ The NPTs surveyed for this study were selected based on the research team's prior background with NPTs ${ }^{8,28,42}$ and our clinical observation of these NPTs being commonly practiced for chronic pain management; we intended to evaluate a diverse range of treatments, though the list is not exhaustive. NPTs for pain that were assessed included (1) clinician-directed NPTs: physical therapy, transcutaneous electrical nerve stimulation (TENS), chiropractic treatment, acupuncture, massage, and CBT group treatments or other psychoeducational courses on pain management; and (2) self-directed NPTs: weight/ strength training, yoga, Tai Chi, pool exercises/swimming, and herbal medicines. Participants rated whether they used each of the 11 NPTs in the past 6 months (yes/no). For NPTs that were endorsed, participants rated the frequency of use on a fourpoint Likert scale ( $1=$ less than once per month, $2=1-3$ times per month, $3=1-3$ times per week, $4=$ most days). Finally, participants rated how helpful each of the pain management techniques were for pain reduction, using a seven-point Likert scale (where $0=$ not at all helpful and $6=$ extremely helpful).

The Chronic Pain Grade (CPG) was used to assess pain intensity and pain-related disability. ${ }^{43}$ The CPG is a commonly used and well-validated measure that provides global scores of pain intensity and pain-related disability. ${ }^{43-45}$ Scores range 
from 0 to 100 , and higher scores indicate more pain intensity or more disability due to pain.

The Pain Self-Efficacy Questionnaire is a ten-item measure of perceived self-efficacy to cope with chronic pain. ${ }^{46}$ Scores range from 0 to 60 , and higher scores indicate higher perceived selfefficacy.

The Patient Health Questionnaire (PHQ) was used to assess depressive symptoms. ${ }^{47}$ The PHQ is a brief, reliable, and valid self-report measure. ${ }^{48,49} \mathrm{We}$ administered the PHQ-8, with scores ranging from 0 to 24 ; higher scores indicate more severe depressive symptoms.

The Generalized Anxiety Disorder-7 Scale is a brief selfreport measure of anxiety symptoms and has been validated as a strong predictor of anxiety disorders. ${ }^{50,51}$ Scores range from 0 to 21 ; higher scores indicate more severe symptoms of anxiety.

The three-item AUDIT-C was used to screen for current hazardous alcohol use. ${ }^{52}$ Hazardous alcohol use was identified by scores $\geq 4$ for men and $\geq 3$ for women. ${ }^{53,54}$

The Drug Abuse Screening Test-10 (DAST-10) is a ten-item measure used to assess abuse of illicit substances. ${ }^{55}$ Potential substance use disorder was defined as a DAST-10 score $\geq 2 .{ }^{55,56}$

EHR-derived Variables. Current prescription opioid status and past-year clinical diagnostic data were extracted from the EHR.

\section{Data Analysis}

Measures of central tendency were conducted to examine the perceived helpfulness of NPT strategies. Pearson correlations were calculated to examine relationships between frequency of use and perceived helpfulness ratings of NPTs. To compare engagement in NPT use in both clinician-directed and selfdirected treatments, participants were divided into four groups (No Engagement, Low Engagement, Moderate Engagement, and High Engagement). Each participant was given an engagement score for both clinician-directed NPT use and self-directed NPT use (0-24 for clinician-directed and 0-20 for self-directed NPTs). Participants who did not endorse any NPTs in the past 6 months were in the "No Engagement" group (score $=0$ ). Participants were included in the "Low Level of Engagement" group with scores of 1-3, "Moderate Level of Engagement" group with scores of 4-6, and "High Level of Engagement" group with scores of 7 or greater (Table 1).
Calculations for clinician-directed NPT engagement and self-directed NPT engagement were based on the sum of the frequency of each NPT use with a four-point Likert scale $(1=$ less than once a month, $2=1-3$ times per month, $3=1-3$ times per week, $4=$ most days) combined with the number of different NPTs participated during the past 6 months. For example, a participant was categorized as high in cliniciandirected engagement if $\mathrm{s} / \mathrm{he}$ endorsed one NPT most days of the week (engagement score $=4$ ) and a second NPT 1-3 times per week (engagement score $=3$ ); this example would result in a total clinician-directed engagement score equal to 7 .

To compare the demographic and clinical variables among the four groups of NPT use for both clinician-directed and selfdirected NPTs, one-way analysis of variance (ANOVA) was utilized for continuous measures and then followed up with Tukey-Kramer post hoc testing. Chi-square tests were conducted for categorical measures. Multinomial regression analyses were performed to model adjusted odds ratios of factors associated with clinician-directed and self-directed NPTs used in the past 6 months. Clinician-directed and self-directed NPT groups were analyzed separately, as the correlation between them was moderate $(r=0.35)$. Continuous variables in the models included age, pain disability, depression, pain-related self-efficacy, and opioid dose. Categorical variables in the model included clinical site, gender, and education. All data analyses were conducted using SAS version 9.4. The a priori alpha level for all inferential analyses was set at 0.05 ; all statistical tests were two-tailed.

\section{RESULTS}

A total of 517 participants enrolled and provided complete data. Frequency analyses examined helpfulness ratings of NPTs for people who reported use of these strategies (Table 2). Strategies were rated as being helpful or very helpful by more than $50 \%$ of users for all treatments assessed (range 51-79\%). CBT or other psychoeducational groups on pain management were rated as helpful by the highest proportion of users (79\% of those that had engaged in them). Pearson correlation coefficients were used to assess relationships between frequency of NPT use and perceived helpfulness. Overall, a positive correlation was found between frequency of use and perceived helpfulness within the group of people who used NPTs. Additionally, the

Table 1 Means and Scores for Number and Use of Non-pharmacological Treatments (NPTs) for Chronic Pain in the Past 6 Months

\begin{tabular}{lllll}
\hline \hline & No Engagement & Low Engagement & Moderate Engagement & High Engagement \\
\hline Clinician-directed NPT & & & & \\
$\quad$ Number of participants per group (\%) & $215(41.6 \%)$ & $117(34.2 \%)$ & $88(17.0 \%)$ & $37(7.2 \%)$ \\
Engagement score & 0 & $1-3$ & $4-6$ & $7-24$ \\
Self-directed NPT & & & & $73(14.1 \%)$ \\
$\quad \begin{array}{l}\text { Number of participants per group (\%) } \\
\text { Engagement score }\end{array}$ & $285(55.1 \%)$ & $109(21.1 \%)$ & $4-6$ & $7-20$ \\
\hline
\end{tabular}

Engagement score was calculated by the sum of the frequency of each NPT use with a four-point Likert scale $(1=$ less than once a month, $2=1-3$ times per month, 3=1-3 times per week, $4=$ most days) combined with the number of different NPTs participated in during the past 6 months 
Table 2 Frequency of Non-pharmacologic Pain Treatment (NPT) Use and Correlations with Helpfulness

\begin{tabular}{llll}
\hline \hline & $\begin{array}{l}\text { \% who used } \\
\text { NPT }\end{array}$ & $\begin{array}{l}\text { \% who perceived } \\
\text { NPT as helpful }\end{array}$ & Pearson correlation \\
& & & \\
\hline Clinician-directed NPT & 26 & 60 & 0.03 \\
$\quad$ Physical therapy & 23 & 55 & 0.28 \\
Transcutaneous electrical nerve stimulation & 11 & 75 & 0.18 \\
Chiropractic & 8 & 53 & -17 \\
Acupuncture & 4 & 79 & 0.07 \\
Group pain management classes & 24 & 74 & 0.16 \\
Massage & & & 0.18 \\
Self-directed NPT & 13 & 51 & 0.29 \\
Herbal medicines & 25 & 57 & 0.41 \\
Weight/strength training & 10 & 60 & 0.15 \\
Yoga & 4 & 53 & 0.33 \\
Tai Chi & 19 & 72 & 0.27 \\
Pool exercises/swimming & & 0.07 \\
\end{tabular}

Helpfulness was rated on a seven-point Likert scale (where $0=$ not at all helpful and $6=$ extremely helpful)

average correlation for self-directed NPTs $(r=0.29)$ was stronger compared to clinician-directed NPTs $(r=0.15)$. Significant positive correlations between frequency of use and perceived helpfulness were identified for TENS $(r=0.28$, $p=0.002)$, herbal medicines $(r=0.29, p=0.02)$, weight/ strength training $(r=0.41, p<0.001)$, and pool exercises/ swimming $(r=0.27, p=0.01)$.

\section{Clinician-Directed NPT Use}

Approximately $42 \%$ of participants indicated they had no clinician-directed NPT use in the past 6 months, 34.2\% were rated as Low Engagement, 17.0\% were rated as Moderate Engagement, and 7.2\% were High Engagement. Betweengroup analyses indicate that age, depression scores, and pain disability differed significantly among the clinician-directed NPT groups (Table 3). Participants in the clinician-directed NPT High Engagement group were younger ( $M=52.4$ years), compared to participants in the No Engagement, Low Engagement, and Moderate Engagement groups $(M=61.5,59.2$, 57.5 years, respectively). Participants in the clinician-directed NPT High Engagement group endorsed more depressive symptoms $(M=12.2)$ compared to participants in the No Engagement, Low Engagement, and Moderate Engagement groups ( $M=9.4,9.2,9.5$ scores, respectively). The High Engagement group had more pain disability $(M=61.1)$ compared to participants in the No Engagement, Low Engagement, and Moderate Engagement groups ( $M=47.7,51.9,50.9$ scores, respectively).

A multinomial regression analysis was conducted to examine factors associated with the use of clinician-directed NPTs for pain (Table 5). Variables included in the analysis were clinical site, age, gender, education, pain disability, depression, pain-related self-efficacy, and opioid dose. Significant associations were identified for younger age and higher pain disability. For every 1 year of increased age, there was a $0.97(95 \%$ $\mathrm{CI}=0.96$ to 0.98 ) probability, or $3 \%$ lower chance of being in a higher clinician-directed NPT engagement category. A one unit increase in the $0-100$ pain disability score would result in being $1.01(95 \% \mathrm{CI}=1.00$ to 1.02$)$ times more likely to be in a higher clinician-directed NPT engagement category.

\section{Self-directed NPT Use}

Approximately $55 \%$ of participants indicated they had no selfdirected NPT use in the past 6 months, $21.1 \%$ were rated as Low Engagement, $14.1 \%$ were rated as Moderate Engagement, and $9.7 \%$ were High Engagement. The only demographic or clinical variable that differed among groups was pain disability score, which was the highest in the High Engagement group $(M=59.4)$ compared to participants in the No Engagement, Low Level of Engagement, and Moderate Level of Engagement groups ( $M=49.0$, 50.5, 51.6 scores, respectively) (Table 4). Post hoc testing revealed that participants in the self-directed NPT High Level of Engagement group reported significantly higher levels of pain disability compared to the No Engagement group $(p=.03)$.

A multinomial regression analysis was conducted to examine factors associated with the use of self-directed NPTs for pain (Table 5). Significant associations were identified for more education and higher pain disability. Compared to patients with high school education or less, those with some college education or technical school on average were $1.80(95 \% \mathrm{CI}=1.13$ to 2.84) times more likely to be in a higher self-directed NPT engagement category, and those with a college degree or more were $2.02(95 \% \mathrm{CI}=1.20$ to 3.40$)$ times more likely to be in a higher self-directed NPT engagement category. A one unit increase in the 0-100 pain disability score would result in being $1.01(95 \% \mathrm{CI}=1.01$ to 1.02$)$ times more likely to be in a higher self-directed NPT engagement category.

\section{DISCUSSION}

Historically, NPTs for management of chronic pain have not been mainstreamed within the US health care system. ${ }^{57}$ This limits patients' access to NPTs and many patients pay out-ofpocket for them. ${ }^{58}$ Allopathic clinicians may not typically provide NPTs and medical providers vary in prescribing or recommending NPTs. ${ }^{59}$ In addition, there are other potential external and internal barriers to engaging in NPTs, such as financial issues or openness to new experiences. ${ }^{60}$ 
Table 3 Group Differences Based on Level of Clinician-Directed Non-pharmacologic Pain Treatment Engagement

\begin{tabular}{|c|c|c|c|c|c|}
\hline & None $(n=215)$ & $\begin{array}{l}\text { Low Engagement } \\
(n=177)\end{array}$ & $\begin{array}{l}\text { Moderate Engagement } \\
(n=88)\end{array}$ & $\begin{array}{l}\text { High Engagement } \\
(n=37)\end{array}$ & $p$ value \\
\hline \multicolumn{6}{|l|}{ Demographic variables } \\
\hline Age (mean) & $61.5(10.9)^{\mathrm{a}, \mathrm{b}}$ & $59.2(11.5)^{\mathrm{a}, \mathrm{b}}$ & $57.5(10.1)^{\mathrm{a}, \mathrm{b}, \mathrm{c}}$ & $52.4(12.7)^{\mathrm{c}}$ & $\dagger 0.01$ \\
\hline Education status & & & & & 0.12 \\
\hline High school or less & $23 \%$ & $23 \%$ & $14 \%$ & $11 \%$ & \\
\hline Some College or Technical school & $55 \%$ & $54 \%$ & $60 \%$ & $49 \%$ & \\
\hline College graduate or more & $22 \%$ & $23 \%$ & $26 \%$ & $41 \%$ & \\
\hline \multicolumn{5}{|l|}{ Marital status } & 0.48 \\
\hline Never married & $7 \%$ & $6 \%$ & $8 \%$ & $8 \%$ & \\
\hline Married/living with partner & $55 \%$ & $60 \%$ & $53 \%$ & $62 \%$ & \\
\hline Divorced/separated & $26 \%$ & $29 \%$ & $30 \%$ & $27 \%$ & \\
\hline Widowed & $12 \%$ & $7 \%$ & $9 \%$ & $3 \%$ & \\
\hline Male gender & $49 \%$ & $52 \%$ & $56 \%$ & $68 \%$ & 0.20 \\
\hline \multicolumn{6}{|l|}{ Clinical variables } \\
\hline Opioid dose & 37.0 & 37.1 & 33.1 & 35.6 & 0.50 \\
\hline Pain disability & $47.7^{\mathrm{a}}$ & $51.9^{\mathrm{a}, \mathrm{b}}$ & $50.9^{\mathrm{a}, \mathrm{b}}$ & $61.1^{\mathrm{b}}$ & $* 0.03$ \\
\hline Pain intensity & 61.4 & 62.5 & 62.8 & 67.9 & 0.08 \\
\hline Depression & $9.4^{\mathrm{a}}$ & $9.2^{\mathrm{a}, \mathrm{b}}$ & $9.5^{\mathrm{a}, \mathrm{b}}$ & $12.2^{\mathrm{b}}$ & $* 0.03$ \\
\hline Anxiety scores & 6.7 & 6.3 & 6.9 & 9.1 & 0.08 \\
\hline Pain-related self-efficacy & 36.1 & 35.9 & 35.9 & 30.9 & 0.15 \\
\hline Hazardous alcohol use & $18.1 \%$ & $11.9 \%$ & $17.0 \%$ & $8.1 \%$ & 0.20 \\
\hline Potential substance use disorder & $12.1 \%$ & $13.0 \%$ & $12.5 \%$ & $12.6 \%$ & 0.46 \\
\hline
\end{tabular}

Scores in this table represent mean (SD) or proportion of the sample

Scores with different superscripts differed significantly on post hoc testing

$* p<0.05$

$t p<0.01$ level

This study provides data on the frequency, correlates of use, and perceived helpfulness of clinician-directed and selfdirected NPT use for chronic pain among patients prescribed LTOT. Participants were a mixed sample of patients enrolled in a private integrated health plan and veterans seeking care in a VA hospital or clinic. This study found that $71.2 \%$ of the sample used one or more NPTs for pain in the past 6 months, and clinician-directed NPT engagement was higher than selfdirected NPT engagement. The utilization of NPTs among patients prescribed LTOT demonstrates that people with chronic pain are open to other treatments beyond mainstream interventions, such as medication. These results may also reflect the overall increase in NPT use among the general population in the USA ${ }^{41}$ and suggest that NPTs may be routinely provided as an option for treatment of chronic pain, since patients report these strategies are helpful for pain management. Additional outcome research on NPTs is necessary to help guide clinical recommendations.

Table 4 Group Differences Based on Level of Self-directed Non-pharmacologic Pain Treatment Engagement

\begin{tabular}{|c|c|c|c|c|c|}
\hline & None $(n=285)$ & $\begin{array}{l}\text { Low Engagement } \\
(n=109)\end{array}$ & $\begin{array}{l}\text { Moderate Engagement } \\
(n=73)\end{array}$ & $\begin{array}{l}\text { High Engagement } \\
(n=50)\end{array}$ & $p$ value \\
\hline \multicolumn{6}{|l|}{ Demographic variables } \\
\hline Age (mean) & $59.9(11.5)$ & $59.0(10.0)$ & $58.6(12.3)$ & $58.3(12.0)$ & 0.75 \\
\hline Education status & & & & & 0.09 \\
\hline High school or less & $24 \%$ & $22 \%$ & $10 \%$ & $12 \%$ & \\
\hline Some college or technical school & $54 \%$ & $51 \%$ & $60 \%$ & $62 \%$ & \\
\hline College graduate or more & $22 \%$ & $27 \%$ & $30 \%$ & $26 \%$ & \\
\hline Marital status & & & & & 0.96 \\
\hline Never married & $6 \%$ & $7 \%$ & $7 \%$ & $6 \%$ & \\
\hline Married/living with partner & $57 \%$ & $54 \%$ & $63 \%$ & $56 \%$ & \\
\hline Divorced/separated & $28 \%$ & $28 \%$ & $22 \%$ & $32 \%$ & \\
\hline Widowed & $10 \%$ & $10 \%$ & $8 \%$ & $6 \%$ & \\
\hline Male gender & $54 \%$ & $52 \%$ & $53 \%$ & $44 \%$ & 0.22 \\
\hline \multicolumn{6}{|l|}{ Clinical variables } \\
\hline Opioid dose & 35.9 & 36.0 & 35.2 & 40.5 & 0.32 \\
\hline Pain disability & $49.0^{\mathrm{a}}$ & $50.5^{\mathrm{a}, \mathrm{b}}$ & $51.6^{\mathrm{a}, \mathrm{b}}$ & $59.4^{\mathrm{b}}$ & $* 0.04$ \\
\hline Pain intensity & 62.6 & 62.4 & 60.0 & 65.5 & 0.14 \\
\hline Depression & 9.5 & 9.3 & 9.1 & 11.0 & 0.24 \\
\hline Anxiety scores & 6.7 & 6.5 & 6.7 & 7.6 & 0.65 \\
\hline Pain-related self-efficacy & 36.0 & 34.4 & 38.1 & 32.8 & 0.11 \\
\hline Hazardous alcohol use & $14.7 \%$ & $12.8 \%$ & $21.9 \%$ & $12.0 \%$ & 0.32 \\
\hline Potential substance use disorder & $17.5 \%$ & $15.6 \%$ & $23.3 \%$ & $10.0 \%$ & 0.27 \\
\hline
\end{tabular}

Scores in this table represent mean (SD) or proportion of the sample

Scores with different superscripts differed significantly on post hoc testing $* p<0.05$ 
Table 5 Multinomial Regression Analyses Examining Factors Associated with Use of Clinician-Directed and Self-directed Non-pharmacologic Pain Treatments (NPTs)

\begin{tabular}{|c|c|c|c|c|}
\hline \multirow[b]{2}{*}{ Variable } & \multicolumn{2}{|c|}{$\begin{array}{l}\text { Variables associated with clinician-directed } \\
\text { NPT }\end{array}$} & \multicolumn{2}{|c|}{ Variables associated with self-directed NPT } \\
\hline & Odds ratio & $95 \%$ confidence interval & Odds ratio & $95 \%$ confidence interval \\
\hline Site & 0.85 & $0.57-1.28$ & 1.11 & $0.73-1.71$ \\
\hline Age & $0.97 *$ & $0.96-0.98$ & 1.00 & $0.98-1.01$ \\
\hline Female gender & 0.87 & $0.58-1.28$ & 1.20 & $0.80-1.80$ \\
\hline Dose & 1.00 & $0.99-1.00$ & 1.00 & $1.00-1.01$ \\
\hline White race/ethnicity & 1.18 & $0.77-1.82$ & 1.06 & $0.68-1.68$ \\
\hline Some college+ & 1.30 & $0.85-1.99$ & $1.80 *$ & $1.13-2.84$ \\
\hline College graduate or more+ & 1.56 & $0.96-2.56$ & $2.02 *$ & $1.20-3.40$ \\
\hline Pain disability & $1.01 *$ & $1.00-1.02$ & $1.01 *$ & $1.01-1.02$ \\
\hline Depression severity & 1.00 & $0.97-1.04$ & 1.00 & $0.97-1.04$ \\
\hline Self-efficacy for managing pain & 1.00 & $0.99-1.02$ & 1.01 & $1.00-1.02$ \\
\hline
\end{tabular}

$+=$ the reference group for this comparison was high school education or less

$* p<0.05$

This study found that participants were using some NPTs at moderately high rates even though there is limited or lacking research evidence for their use, such as TENS. ${ }^{24,25}$ Participants reported also using other NPTs at moderately high rates, such as physical therapy and exercise, which is consistent with guidelines for chronic pain. ${ }^{6-11}$ More than half of users for all NPTs rated their use as helpful or very helpful (range of 51$79 \%$ ). Some of the most highly rated NPTs, such as group pain management classes, chiropractic, pool exercises/swimming, and yoga, had lower engagement rates. The differences in extent of engagement among the NPTs may be related to availability, access, prescription of the treatment, insurance coverage, or other factors. NPTs were rated as helpful among most patients who engaged in them, suggesting a need to better understand barriers to their use and testing of interventions to enhance participation.

This study revealed some demographic and clinical factors related to NPT use, which may facilitate wider implementation. Patients who reported higher education were more likely to use self-directed NPTs for chronic pain; however, this relationship was not found for cliniciandirected NPTs, which suggests that education relates to the types of NPTs that one may engage in. Younger age was mildly associated with clinician-directed NPT use. This finding is consistent with other research ${ }^{29,41,66,67}$ and suggests differences in life experience, familiarity, knowledge, access, affordability, and/or willingness to engage in NPTs. However, it is unclear why age was related to clinician-directed but not self-directed NPT use. Future studies may examine reasons why these demographic variables are associated with increased NPT use and potentially develop strategies to engage other individuals in clinician-directed and self-directed NPTs for chronic pain.

We also found that patients who reported higher pain disability were slightly more likely to use both clinician-directed and self-directed NPTs, though the magnitude of this effect was small. Similarly, other research has found that individuals with higher pain disability utilize more medical services/treatments. ${ }^{61,62}$ This suggests that people with higher levels of pain disability may be more encouraged or willing to participate in a variety of different NPTs for chronic pain. The clinical effectiveness of these interventions should be assessed regularly to assist in formulating patients' treatment plans. ${ }^{63,64}$ Assessment of NPT utility can reduce burden on patients and financial costs by focusing on NPTs that are most helpful and eliminating those that are less effective. ${ }^{58,65}$

There are several limitations to this study. Although our measure of NPT was based on prior research, it was brief, and others may differ on how to categorize levels of such use. Additionally, the breadth of NPTs that were surveyed could be expanded to include injections or other medical procedures, other psychological approaches such as meditation or biofeedback, and other complementary and integrative health treatments. The study is cross-sectional, so no causal associations can be made. In addition, participants were asked to rate their use and perceived effectiveness of NPTs retrospectively, and recall may be inaccurate. Future research could benefit from collecting data closer in proximity to actual use of NPTs, potentially using electronic tracking devices. The present study did not address the clinical effectiveness of the NPTs; future studies could assess utilization of NPTs in more depth by weighing the frequency of NPT use with the recommended dose. We were unable to equally assess each of the 11 treatments due to power limitations. Satisfaction with NPT use was based on self-report and we did not assess quality of participation or evaluate if clinicians who administered NPTs were licensed professionals. Also, this study was unable to assess reimbursement or the fees for NPTs, which could have impacted level of engagement. Lastly, our results are limited by the specific samples assessed and may not generalize to other patients and settings, though recruitment from two different health systems may aid generalizability.

Non-pharmacological interventions for chronic pain are noninvasive and recommended for use by pain treatment guidelines. ${ }^{25}$ Based on results from this study, both clinician-directed and self-directed NPTs are also perceived to be beneficial by the majority of patients. Although greater utilization of these strategies is recommended, it may be difficult for some individuals 
to engage in NPTs. Our findings suggest that certain groups could be targeted for engagement, such as people who have less education, older individuals, and those with more impairment due to pain. Future research should investigate strategies for increasing use of NPTs for patients with chronic pain.

Corresponding Author: Crystal C. Lozier, PhD; VA Portland Health Care System, Portland, OR, USA (e-mail: crystal.lozier@va.gov).

\section{Compliance with Ethical Standards:}

Study procedures were reviewed, approved, and monitored by Institutional Review Boards at both study settings. All participants provided written informed consent to participate.

Conflict of Interest: Research reported in this manuscript was supported by grant 034083 from the National Institute on Drug Abuse of the National Institutes of Health. Dr. Lozier was funded in part by Mental Illness Research, Education and Clinical Center at the VA Portland Health Care System. The work was also supported by resources from the VA Health Services Research and Development-funded Center to Improve Veteran Involvement in Care at the VA Portland Health Care System (CIN 13-404). Dr. Yarborough has received grant support from Purdue Pharma LP, and the Industry PMR Consortium, a consortium of 10 companies working together to conduct FDA-required post-marketing studies that assess known risks related to extended-release, longacting opioid analgesics. Dr. Deyo receives royalties from UpToDate for authoring topics on low back pain. He received a financial award from NuVasive, as part of a lifetime achievement award from the International Society for Study of the Lumbar Spine. No other author reports having any potential conflict of interest with this study. The content of this manuscript is solely the responsibility of the authors and does not necessarily represent the official views of the Department of Veterans Affairs or the National Institute on Drug Abuse.

\section{REFERENCES}

1. Institute of Medicine. Relieving pain in America: A blueprint for transforming prevention, care, education, and research. Washington, DC: The National Academies Press; 2011.

2. Deyo, RA, Von Korff M, Duhrkoop D. Opioids for low back pain. BMJ. 2015;350:g6380

3. Chou R, Turner JA, Devine EB, et al. The effectiveness and risks of longterm opioid therapy for chronic pain: A systematic review for a National Institutes of Health Pathways to Prevention Workshop. Ann Intern Med. 2015; 162:276-286.

4. Dowell D, Haegerich TM, Chou R. CDC guideline for prescribing opioids for chronic pain-United States. JAMA. 2016;315:1624-1645.

5. Chang, KL Fillingim, R, Hurley, RW, Schmidt, S. Chronic pain management: Nonpharmacological therapies for chronic pain. FP Essentials. 2015;432:21-26.

6. Beumer L, Wong J, Warden SJ, et al. Effects of exercise and manual therapy on pain associated with hip osteoarthritis: A systematic review and meta-analysis. Br J Sports Med. 2016;50(8):458-463.

7. Cheng $\mathrm{CH}$, Su HT, Yen LW, et al. Long-term effects of therapeutic exercise on nonspecific chronic neck pain: A literature review. $J$ Phys Ther Sci. 2016;27(4): 1271-1276.

8. Chou R, Deyo R, Friedly J, Skelly A, et al. Nonpharmacologic Therapies for Low Back Pain: A Systematic Review for an American College of Physicians Clinical Practice Guideline. Ann of Intern Med. 2017; 166(7):493-505.

9. Fransen M, McConnell S, Hernandez-Molina G, et al. Exercise for osteoarthritis of the hip. Cochrane Database Syst Rev. 2014;4:CD007912.

10. Gomes-Neto M, Lopes JM, Conceição CS, et al. Stabilization exercise compared to general exercises or manual therapy for the management of low back pain: A systematic review and meta-analysis. Phys Ther Sport. 2017:23:136-142.

11. Haik MN, Alburquerque-Sendin F, Moreira RF, et al. Effectiveness of physical therapy treatment of clearly defined subacromial pain: A systematic review of randomised controlled trials. $\mathrm{Br} J$ Sports Med. 2016;50(18):1124-1134
12. Cramer, H, Klose, P, Brinkhaus, B, Michalsen, A, Dobos, G. Effects of yoga on chronic neck pain: A systematic review and meta-analysis. Clinical Rehab. 2017;0269215517698735.

13. Crawford, C, Boyd, C, Paat, CF, Price, A, Xenakis, L, Yang, E. Evidence for massage therapy (EMT) working group. The impact of massage therapy on function in pain populations-A systematic review and meta-analysis of randomized controlled trials: Part I, patients experiencing pain in the general population. Pain Medicine. 2016;17:1353-1375.

14. Jonas WB, Schoomaker E, Berry K, Buckenmaier III C. A time for massage. Pain Medicine 2016;1-2.

15. Furlan AD, Giraldo M, Baskwill A, Irvin E, Imamura M. Massage for lowback pain. Cochrane Database Syst Rev.2015;1(9):CD001929.

16. Vranceanu, AM, Stone, M, Wallace, T, Kulich, R. Cognitive behavioral therapy for chronic pain. in the Massachusetts General Hospital Handbook of Behavioral Medicine. Springer Int Publ. 2017;93-114.

17. Law D, McDonough S, Bleakley C, Baxter GD, Tumilty, S. Laser acupuncture for treating musculoskeletal pain: a systematic review with meta-analysis. J Acupunct Meridian Stud. 2015; 8(1):2-16.

18. Manheimer E, White A, Berman B, et al. Meta-analysis: Acupuncture for low back pain. Ann Intern Med. 2005; 142(8):651-663.

19. Vickers, AJ, Cronin, AM, Maschino, AC, Lewith, G, Macpherson, H, Victor, N, Linde, K. Individual patient data meta-analysis of acupuncture for chronic pain: protocol of the Acupuncture Trialists' Collaboration. Trials. 2010;11, 90.

20. Hall A, Copsey B, Richmond H, et al. Effectiveness of Tai Chi for chronic musculoskeletal pain conditions: Updated systematic review and metaanalysis. Phys Ther. 2017;97(2):227-238.

21. Jiang D, Kong W, Jiang J. The role of Tai Chi in mental health management-Lessons learned from clinical trials. Reviews on recent clinical trials. 2016;11:324-32.

22. Tousignant-Laflamme, Y, Laroche, C, Beaulieu, C, Bouchard, AJ, Boucher, S, Michaud-Létourneau, M. A randomized trial to determine the duration of analgesia following a 15-and a 30-minute application of acupuncture-like TENS on patients with chronic low back pain. Physiotherapy Theory and Practice. 2017;1-9.

23. Ely S. Transcutaneous electrical nerve stimulation (TENS) at acupuncture points for the management of chronic pain: A narrative review. Physiotherapy. 2016; 102:e90.

24. Khadilkar A, Odebiyi DO, Brosseau L, et al. Transcutaneous electrical nerve stimulation (TENS) versus placebo for chronic low-back pain. Cochrane Database Syst Rev. 2008;8(4): CD003008.

25. Qaseem A, Wilt T, McLean R, Forciea MA. Noninvasive Treatments for Acute, Subacute, and Chronic Low Back Pain: A Clinical Practice Guideline from the American College of Physicians. Ann of Intern Med. 2017; 166(7):514-530.

26. Martin BI, Gerkovich MM, Deyo RA, et al. The association of complementary and alternative medicine use and health care expenditures for back and neck problems. Med Care. 2012;50(12):1029-1036.

27. Hu XY, Chen NN, Chai QY, et al. Integrative treatment for low back pain: An exploratory systematic review and meta-analysis of randomized controlled trials. Chin J Integr Med. 2015;1-3.

28. Denneson LM, Corson K, Dobscha SK. Complementary and alternative medicine use among Veterans with chronic noncancer pain. $J$ Rehabil Res Dev. 2011;48(9):1119-1128.

29. Fleming S, Rabago DP, Mundt MP, Fleming MF. CAM therapies among primary care patients using opioid therapy for chronic pain. BMC Complement Altern Med. 2007;16:7-15.

30. Sherman KJ, Cherkin DC, Connelly MT, et al. Complementary and alternative medical therapies for chronic low back pain: What treatments are patients willing to try? BMC Complement Altern Med. 2004;19:4-9.

31. Barnes PM, Bloom B, Nahin RL. Complementary and alternative medicine use among adults and children: United States, 2007. Natl Health Stat Report. 2008;12:1-23.

32. Dart RC, Surratt HL, Cicero TJ, et al. Trends in opioid analgesic abuse and mortality in the United States. N Engl J Med. 2015;372:241-248.

33. Frieden TR, Houry D. Reducing the risks of relief: The CDC opioidprescribing guideline. N Engl J Med. 2016;in press.

34. Lovejoy TI, Morasco BJ, Demidenko MI, et al. Reasons for discontinuation of long-term opioid therapy in patients with and without substance use disorders. Pain. 2017;158:526-534.

35. Morasco BJ, Yarborough BJ, Smith NX, et al. Higher prescription opioid dose is associated with worse patient-reported pain outcomes and more health care utilization. J Pain. 2017;18(4):437-445.

36. Gureje O, Von Korff M, Simon GE, et al. Persistent pain and wellbeing: A World Health Organization study in primary care. JAMA. 1998;280:145151. 
37. Edlund MJ, Steffick D, Hudson T, et al. Risk factors for clinically recognized opioid abuse and dependence among Veterans using opioids for chronic non-cancer pain. Pain. 2007;(129):355-362.

38. Von Korff M, Saunders K, Ray G, et al. De facto long-term opioid therapy for non-cancer pain. Clin J Pain. 2008;24:521-527.

39. Astin JA. Why patients use alternative medicine: results of a national study. JAMA. 1998;279(19):1548-1553.

40. Eisenberg DM, Kessler RC, Foster C, Norlock, FE, Calkins DR, Delbanco TL. Unconventional medicine in the United States. Prevalence, costs, and patterns of use. N Engl J Med. 1993;328(4):246-252.

41. Kessler RC, Davis RB, Foster DF, et al. Long-term trends in the use of complementary and alternative medical therapies in the United States. Ann Intern Med. 2001;135(4): 262-268.

42. DeBar LL, Elder C, Ritenbaugh C, Aickin M, Deyo RA, Meenan R, Dickerson J, Webster JA, Yarborough BJ. Acupuncture and chiropractice care for chronic pain in an integrated health plan: A mixed methods study. BMC Complement Altern Med. 2011;11:118.

43. Von Korff M, Ormel J, Keefe FJ, et al. Grading the severity of chronic pain. Pain. 1992;50(2):133-149.

44. Smith BH, Penny KI, Purves AM, et al. The Chronic Pain Grade questionnaire: Validation and reliability in postal research. Pain. 1997;71:141-147.

45. Elliott AM, Smith BH, Smith WC, Chambers WA. Changes in chronic pain severity over time: The Chronic Pain Grade as a valid measure. Pain 2000;88(3):303-308.

46. Nicholas, MK. The Pain Self-Efficacy Questionnaire: Taking pain into account. Eur J Pain. 2007;11:153-163.

47. Kroenke K, Spitzer RL. The PHQ-9: A new depression diagnostic and severity measure. Psychiatr Ann. 2002;32:509-515.

48. Spitzer RL, Kroenke K, Williams JB. Validation and utility of a self-report version of PRIME-MD: The PHQ primary care study. JAMA. 1999;282:1737-1744.

49. Kroenke K, Spitzer RL, Williams JB. The PHQ-9: Validity of a brief depression severity measure. J Gen Intern Med. 2001;16:606-613.

50. Spitzer RL, Kroenke K, Williams JBW, Lowe B. A brief measure for assessing generalized anxiety disorder: The GAD-7. Arch of Intern Med. 2006; 166:10:1092-1097.

51. Kroenke K, Spitzer RL, Williams JB, Monahan PO, Lowe B. Anxiety disorders in primary care: prevalence, impairment, comorbidity, and detection. Ann Intern Med. 2007; 146: 317-325.
52. Bush K, Kivlahan DR, McDonnel MB, et al. The AUDIT alcohol consumption questions (AUDIT-C). Arch Intern Med. 1998;158:1789-1795.

53. Bradley KA, DeBenedetti AF, Volk RJ, Williams EC, Frank D, Kivlahan DR. AUDIT-C as a brief screen for alcohol misuse in primary care. Alcohol Clin Exp Res. 2007;31:1208-1217.

54. Frank D, DeBenedetti AF, Volk RJ, Williams EC, Kivlahan DR, Bradley KA. Effectiveness of the AUDIT-C as a screening test for alcohol misuse in three race/ethnic groups. J Gen Int Med. 2008;23:781-787.

55. Skinner HA. The Drug Abuse Screening Test. Addict Behav. 1982;7:363-371.

56. Cocco KM, Carey KB. Psychometric properties of the Drug Abuse Screening Test in psychiatric outpatients. Psychol Assess. 1998;10:408-414.

57. Jonas WB, Eisenberg D, Hufford D, Crawford C. The evolution of complementary and alternative medicine (CAM) in the USA over the last 20 years. Forsch Komplementmed. 2013;20(1):65-72.

58. Herman PM, Poindexter BL, Witt CM, Eisenberg DM. Are complementary therapies and integrative care cost-effective? A systematic review of economic evaluations. BMJ Open. 2012;2(5):e001046.

59. Gaul C, Eismann R, Schmidt T, et al. Use of complementary and alternative medicine in patients suffering from primary headache disorders. Cephalalgia. 2009;29:1069-1078.

60. Sirois FM, Gick ML. An investigation of the health beliefs and motivations of complementary medicine clients. Soc Sci Med. 2002;55:1025-1037.

61. Hing E, Cherry DK, Woodwell DA. National Ambulatory Medical Care Survey: 2004 summary. Adv Data. 2006;1-33.

62. Luo X, Pietrobon R, Sun SX, et al. Estimates and patterns of direct health care expenditures among individuals with back pain in the United States. Spine. 2004;29:79-86.

63. Coulter ID, Willis EM. The rise and rise of complementary and alternative medicine: A sociological perspective. Med J Austral. 2004;180(11):587-589.

64. Nahin RL, Straus SE. Research into complementary and alternative medicine problems and potential. BMJ. 2001;322:161-164.

65. Gore M, Sadosky A, Stacey BR, Tai KS, Leslie D. The burden of chronic low back pain: clinical comorbidities, treatment patterns, and health care costs in usual care settings. Spine. 2012;37:E668-E677.

66. Saper RB, Eisenberg DM, Davis RB, Culpepper L, Phillips RS. Prevalence and patterns of adult yoga use in the United States: Results of a national survey. Altern Ther Health Med. 2004;10:44-49.

67. Tindle HA, Davis RB, Phillips RS, Eisenberg DM. Trends in use of complementary and alternative medicine by US adults: 1997-2002. Altern Ther Health Med. 2005;11:42-49. 